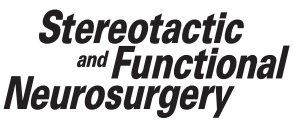

Stereotactic

Neurosurgery
Stereotact Funct Neurosurg 2013;91:69-78

DOI: $\underline{10.1159 / 000342492}$
Received: October 14, 2011

Accepted after revision: August 2, 2012

Published online: January 22, 2013

\title{
Pathways of Infusate Loss during Convection-Enhanced Delivery into the Putamen Nucleus
}

\author{
Martin L. Brady ${ }^{\mathrm{a}}$ Raghu Raghavan ${ }^{\mathrm{a}} \quad$ Andrew Alexander $^{\mathrm{b}-\mathrm{d}}$ Ken Kubotag \\ Karl Sillay ${ }^{e}$ Marina E. Emborg ${ }^{c, f}$ \\ a Therataxis LLC, Baltimore, Md., b Waisman Center, Departments of ${ }^{\mathrm{c} M e d i c a l}$ Physics, ${ }^{\mathrm{d}}$ Psychiatry, ${ }^{\mathrm{e}}$ Neurosurgery \\ and ${ }^{\mathrm{f} P r e c l i n i c a l}$ Parkinsons Research Program, Wisconsin National Primate Research Center, University of \\ Wisconsin, Madison, Wisc., and ${ }^{9}$ Kinetics Foundation, Los Altos, Calif., USA
}

\section{Key Words}

Parkinson's disease - Convection-enhanced delivery • Intraputaminal infusion • Magnetic resonance imaging

\begin{abstract}
Background: New strategies aiming to treat Parkinson's disease, such as delivery of trophic factors via protein infusion or gene transfer, depend upon localized intracerebral infusion, mainly into the putamen nucleus. Convection-enhanced delivery (CED) has been proposed as a method to improve intracerebral distribution of therapies. Yet analysis of controversial results during the clinical translation of these strategies suggests that intracerebral misdistribution of infusate may have affected the outcomes by limiting the amount of treatment into the target region. Objectives: This study aimed to identify possible pathways of infusate loss and their relative impact in the success of targeted CED into the postcommissural ventral putamen nucleus. Methods: Thirteen adult macaque monkeys received intraputaminal CED infusions of $100 \mu \mathrm{l}$ of $2.0 \mathrm{~mm}$ gadoteridol and bromophenol blue $(0.16 \mathrm{mg} / \mathrm{ml})$ solution at a rate of $1.0 \mu \mathrm{l} / \mathrm{min}$ under intraoperative magnetic resonance imaging (MRI) guidance. Quantitative maps of infusate concentration were computed at 10-min intervals throughout the procedure in
\end{abstract}

\section{KARGER}

E-Mail karger@karger.ch www.karger.com/sfn

\section{(c) 2013 S. Karger AG, Basel} 1011-6125/13/0912-0069\$38.00/0

Karge

0 pen access

This is an Open Access article licensed under the terms of the Creative Commons Attribution-NonCommercialNoDerivs 3.0 License (www.karger.com/OA-license), applicable to the online version of the article only. Distribution for non-commercial purposes only. a 3-Tesla MRI scanner. The fraction of tracer lost from the putamen as well as the path of loss were evaluated and quantified for each infusion. Results: All injections (total 22) were successfully placed in the ventral postcommissural putamen nucleus. Four major paths of infusate loss from the putamen were observed: overflow across putamen boundaries, perivascular flow along large blood vessels, backflow along the inserted catheter and catheter tract leakage into the vacated catheter tract upon catheter removal. Overflow loss was observed within the first $30 \mu \mathrm{l}$ of infusion in all cases. Measurable tracer loss following the path of an artery out of the putamen was observed in 15 cases, and in 8 of these cases, the loss was greater than $10 \%$ of infusate. Backflow that exited the putamen was observed in 4 cases and led to large loss of infusate ( $80 \%$ in 1 case) into the corona radiata. Loss into the vacated catheter tract amounted only to a few microliters. Conclusions: Our analysis demonstrates that after controlling for targeting, catheter type, infusion rate and infusate, the main issues during surgical planning are the identification of appropriate infusate volume that matches the target area, as well as mapping the regional vasculature as it may become a pathway for infusate loss. Most importantly, these results underscore the significance of presurgical planning for catheter placement and infusion, and the value of imaging guidance to ensure targeting accuracy.

Copyright $\odot 2013$ S. Karger AG, Basel

Martin Brady

Therataxis, LLC

1101 E. 33rd Street

Ste. B305, Baltimore, MD 21218 (USA)

E-Mail mbrady@therataxis.com 


\section{Introduction}

The putamen nucleus has been identified as a target for novel strategies involving intraparenchymal delivery of protein and gene therapies for Parkinson's disease [15]. While there have been several phase I clinical trials that suggest possible efficacy of trophic factors infused directly into the putamen $[4,6,7]$, the efficacy of these strategies has not been confirmed in a controlled phase II study $[1,2]$. Inadequate delivery has been speculated to be a possible factor for the failure of these trials. For example, it has been suggested that the failure in a phase II trial for delivery of glial-derived neurotrophic factor (GDNF) was due to variations in catheter placement that affected protein distribution and diminished availability to the target [8]. The importance of appropriate target coverage is further highlighted in a report on the postmortem analysis of 2 patients that were part of a phase II clinical gene therapy trial to assess the effect of adenoassociated virus serotype 2/2 (AAV2) encoding for the neurotrophic factor neurturin. The investigators stated that despite the patients receiving 8 AAV2 neurturin inoculations spread across the putamen, only $15 \%$ of the structure was covered [9]. The importance of appropriate infusate concentrations and coverage of targeted structures for therapeutic efficacy is further highlighted in nonhuman primate (NHP) studies demonstrating a relationship between intraputaminal levels of GDNF protein and significant behavioral improvements [10, 11].

Convection-enhanced delivery (CED) has been proposed as a method to maximize infusate distribution [12] and reduce the number of intracerebral injections, therefore decreasing the risks associated with each brain penetration [13]. CED methods have been reported in a number of clinical trials with different degrees of success [1-4, $7,14]$. A CED infusion is expected to generate a spherical cloud of infusate emerging from the catheter tip [15], yet a symmetrical sphere does not match the elongated profile of the putamen. Furthermore, as the outer boundaries of the nucleus do not present a barrier to fluid flow, infusion carries the risk of unintentionally affecting neighboring structures. The putamen nucleus is surrounded by white matter tracts (corona radiata, internal capsule and external capsule) which are known to be more conductive than gray matter [16]. Similarly, the perivascular space of blood vessels near the infusion catheter also provides paths of low resistance and preferred flow for fluids [17]. While these channels are naturally occurring in the brain, the surgical procedures needed for the infusion in themselves can create paths of low fluid resistance, such as the 'annulus' surrounding the catheter formed during its insertion and the tract left by the withdrawal of the catheter after infusion [16].

In this report, we aimed to evaluate patterns of infusate distribution in the putamen nucleus in order to identify possible pathways of infusate loss and their relative impact on the success of targeted CED into the postcommissural ventral putamen nucleus. Taking advantage of intraoperative magnetic resonance imaging (IMRI) technology, we obtained three-dimensional maps of gadolinium concentration during the intracerebral infusions, using our previously described method [18]. Thus, we were able to quantify the dose of tracer and its distribution in the brain, tracking the tracer in both time and space.

\section{Methods}

Subjects

Five adult female rhesus monkeys (Macaca mulatta) and 8 adult female cynomolgus monkeys (Macaca fascicularis) were used in this study. Animals were housed individually on a 12hour light/dark cycle and received food and water ad libitum. The animals' diet was supplemented with fruit during daily enrichment. All efforts were made to ameliorate suffering of animals. This study was performed in strict accordance with the recommendations in the Guide for the Care and Use of Laboratory Animals of the National Institutes of Health. The protocol was approved by the Institutional and Animal Care Committee of the University of Wisconsin, Madison (permit No. G00554). Age, weight and putaminal sizes of each subject are contained in online supplementary table S1 (for all online suppl. material, see www. karger.com/doi/10.1159/000342492).

\section{Surgery and Targeting Method}

Catheters were targeted to the ventral postcommissural right and/or left putamen, approximately $1-2 \mathrm{~mm}$ posterior to the coronal plane presenting the anterior commissure using an MRIcompatible external trajectory guide (Navigus, Medtronic Inc., Minneapolis, Minn., USA). The planned trajectories were centered laterally at least $5 \mathrm{~mm}$ deep within the putamen. The sterile surgical procedure followed our previously published protocol [19]. Briefly, the animal was put under isoflurane (1-3\%), its vital signs monitored and placed in a MRI-compatible stereotaxic frame using the coordinates obtained during a baseline MRI. The entry point (identified in the baseline MRI) was located on the surface of the skull. Craniotomies $8-12 \mathrm{~mm}$ in diameter were drilled at the planned entry area corresponding to the opening of the trajectory guide base. The dura was retracted to expose the brain, and the trajectory guide base was mounted to the skull over the craniotomy. In the MRI suite, a cannula filled with sterile degassed water was inserted into the stem of the trajectory guide. Targeting (3D, T1-weighted) MRI scans were taken to position the cannula guide in the anterior-posterior (AP) and mediolateral (ML) planes. When the trajectory angle of the fluid-filled can- 
Table 1. Infusate distribution measurements for all 22 infusions

\begin{tabular}{|c|c|c|c|c|c|c|c|c|c|c|c|}
\hline \multirow[t]{2}{*}{ Animal } & \multirow[t]{2}{*}{ Side } & \multirow[t]{2}{*}{ Cath. } & \multirow{2}{*}{$\begin{array}{l}\text { Depth } \\
\text { mm }\end{array}$} & \multirow{2}{*}{$\begin{array}{l}\text { Tip dist. } \\
\mathrm{mm}\end{array}$} & \multirow{2}{*}{$\begin{array}{l}\text { Backflow } \\
\mathrm{mm}\end{array}$} & \multirow{2}{*}{$\begin{array}{l}\text { Withdrawal } \\
\text { min }\end{array}$} & \multicolumn{3}{|c|}{ Loss fraction at $30 \mu \mathrm{l}, \%$} & \multicolumn{2}{|c|}{ Loss fraction at $100 \mu \mathrm{l}, \%$} \\
\hline & & & & & & & perivascular & backflow & overall & backflow & overall \\
\hline R95106 & $\mathrm{r}$ & VT & 6.0 & 2.5 & 2.0 & 12 & 3 & & 6 & & 24 \\
\hline R03044 & $\mathrm{r}$ & VT & 6.5 & 2.5 & 4.0 & 13 & 8 & & 11 & & 30 \\
\hline R03044 & 1 & VT & 6.5 & 2.0 & 4.0 & 13 & 7 & & 22 & & 38 \\
\hline Cy0140 & 1 & VT & 6.0 & 2.5 & 13.0 & 12 & 1 & 62 & 67 & 70 & 76 \\
\hline Сy0286 & 1 & VT & 4.5 & 0.5 & 3.0 & 16 & 20 & & 34 & & 52 \\
\hline Сy0287 & $\mathrm{r}$ & VT & 7.0 & 1.5 & 3.0 & 19 & 14 & & 18 & & 40 \\
\hline Сy0288 & $\mathrm{r}$ & VT & 5.5 & 0.5 & 3.5 & 16 & 0 & & 23 & & 40 \\
\hline Сy0295 & $\mathrm{r}$ & VT & 5.0 & 1.5 & 8.0 & 17 & 0 & 7 & 14 & 43 & 51 \\
\hline Сy0286 & $\mathrm{r}$ & NS & 7.0 & 0.7 & 3.5 & 14 & 20 & & 42 & & 52 \\
\hline Сy0287 & 1 & NS & 9.0 & 1.5 & 3.0 & 18 & 35 & & 41 & & 56 \\
\hline Сy0288 & 1 & NS & 4.5 & 2.0 & 6.0 & 17 & 0 & 8 & 20 & 29 & 49 \\
\hline Су0295 & 1 & NS & 5.0 & 1.5 & 3.0 & 21 & 31 & & 33 & & 51 \\
\hline Су0298 & $\mathrm{r}$ & FM & 6.0 & 1.8 & 4.0 & 30 & 0 & & 3 & & 21 \\
\hline Сy0299 & $\mathrm{r}$ & FM & 5.5 & 1.5 & 3.5 & 13 & 25 & & 30 & & 47 \\
\hline Су0279 & $\mathrm{r}$ & FM & 6.0 & 1.0 & 4.0 & 12 & 11 & & 13 & & 40 \\
\hline \multicolumn{3}{|c|}{ Mean $\pm S D$} & $6.2 \pm 1.1$ & $1.6 \pm 0.7$ & $5 \pm 3.4$ & & $9.4 \pm 10.9$ & & $24 \pm 16$ & & $44 \pm 13$ \\
\hline
\end{tabular}

'Cath.' refers to the catheter tip type: VT = valve tip (stylet end port); $\mathrm{VT}^{*}=$ valve tip, occluded before retrieval; $\mathrm{NS}=$ no stylet end port; $\mathrm{FM}=$ fiber mesh. Side: $\mathrm{r}=$ right; $\mathrm{l}=$ left. Depth refers to the length of catheter inside the putamen. Tip dist. is the distance from the catheter tip to the nearest putamen boundary. Backflow is the extent of tracer reflux visible along the catheter shaft visible $10 \mathrm{~min}$ after the start of the infusion. Withdrawal refers to the time between the end of infusion and removal of the catheter. Loss fractions (perivascular, backflow, and total) are the fractions of the total measured amounts of infusate that are outside the putamen. nula was confirmed to be on target, the alignment stem was locked into position, the guiding insert and the remote introducer were placed in the guiding stem and the catheter for the infusion was threaded and fastened to the remote introducers by a locking mechanism.

\section{Infusion}

Custom-made stepped catheters were used in this project. They consisted of a fused silica shaft with an outside diameter $0.65 \mathrm{~mm}$ and inside diameter $0.32 \mathrm{~mm}$. A 3-mm-length tip with outer diameter $0.36 \mathrm{~mm}$ and inner diameter $0.25 \mathrm{~mm}$ extended from the end of the shaft. Three variations of the tip design were tested (table 1): a polyimide open-end port with a stylet to close the port during insertion $(\mathrm{n}=14)$; the same polyimide tip used without a stylet $(\mathrm{n}=5)$; and a microporous-walled tip material with closed end $(n=3)$. As we did not observe major differences in the infusion pathways between these catheter variations, the data of all infusions were considered in the analysis.

Silica infusion lines were used to connect the catheter to $5-\mathrm{cm}^{3}$ Hamilton gas-tight syringes. The syringes were driven by an
MRI-compatible syringe pump (PHD 2000, Harvard Apparatus, Holliston, Mass., USA) placed at approximately the same height as the catheter tip. Line pressure was monitored continuously throughout the infusion. The catheter was introduced into the brain, advancing the remote introducer at approximately 5-20 $\mathrm{mm} / \mathrm{min}$.

The infusate was a solution of gadoteridol $(2 \mathrm{mmol} / \mathrm{l}$; ProHance, Bracco Diagnostics Inc., Princeton, N.J., USA) and bromophenol blue $(0.16 \mathrm{mg} / \mathrm{ml}$; Sigma Aldrich, St. Louis, Mo., USA) in phosphate-buffered saline. A volume of $100 \mu \mathrm{l}$ was infused at an average flow rate of $1.0 \mu \mathrm{l} / \mathrm{min}$ in each infusion. After the infusion was completed, the catheter was left in place for approximately 10-30 min before withdrawal. In 1 case (Cy0279-left), the stylet was replaced to cover the end port before catheter withdrawal.

\section{MRI Acquisition}

Imaging was performed in a 3-Tesla GE Signa (GE Healthcare; Waukesha, Wisc., USA) MRI scanner with a custom 3-inch diameter, receive-only surface coil (MR Instruments, Inc., Minneap- 
olis, Minn., USA) as previously described [19]. Presurgical MRI scans included three-dimensional T1W images with an inversion recovery (IR)-prepped, fast-gradient echo (IR-fGRE) sequence. The scanning parameters were: inversion time $\left(\mathrm{T}_{\mathrm{I}}\right)=450 \mathrm{~ms}$, repetition time $\left(\mathrm{T}_{\mathrm{R}}\right)=9.2 \mathrm{~ms}$, echo time $\left(\mathrm{T}_{\mathrm{E}}\right)=4.1 \mathrm{~ms}$, receiver bandwidth $= \pm 25 \mathrm{kHz}$. The matrix size was $256 \times 224 \times 128,140 \times$ $105 \mathrm{~mm}$ in-plane FOV. The scans produced $0.8-\mathrm{mm}$-thick slices at $0.4 \mathrm{~mm}$ spacing, reconstructed in plane to $0.27 \times 0.27-\mathrm{mm}$ voxels in a scan time of 7:50 min. Presurgical MRI angiography was obtained using a T1W high-resolution spoiled gradient echo (SPGR) sequence with $\mathrm{T}_{\mathrm{R}}=15 \mathrm{~ms}, \mathrm{~T}_{\mathrm{E}}=3.7 \mathrm{~ms}$, flip angle $=30^{\circ}$, matrix size $256 \times 256 \times 312,140 \mathrm{~mm}$ in-plane FOV, slice thickness $=0.6 \mathrm{~mm}$, slice separation $=0.3 \mathrm{~mm}$. The slices were reconstructed at $0.27 \times 0.27 \mathrm{~mm}$ in plane voxels. The acquisition was repeated twice both before and after $(5 \mathrm{~min})$ intravenous injection of a single dose of Prohance contrast agent $(0.2 \mathrm{ml} / \mathrm{kg}$ equivalent to $0.1 \mathrm{mmol} / \mathrm{kg}$ ).

During the infusions, a pair of 3D SPGR scans with different flip angles $\left(6^{\circ}\right.$ and $\left.34^{\circ}\right)$ was used to map T1 $\left(\mathrm{T}_{\mathrm{R}}=21 \mathrm{~ms}, \mathrm{~T}_{\mathrm{E}}=\right.$ $6 \mathrm{~ms}$, in-plane FOV $=140 \times 105 \mathrm{~mm}(0.75$ phase FOV $)$, matrix $=$ $256 \times 224,64$ contiguous coronal slices each 1.6 or $0.8 \mathrm{~mm}$ thick). A pair was acquired just prior to the start of infusion as a baseline, and then the pair was repeated at approximately 9 -min intervals during the infusion.

\section{MRI after Processing}

Contrast Agent Concentration Measurements. T1 maps were computed from consecutive pairs of 3D SPGR scans at $6^{\circ}$ and $34^{\circ}$ flip angles using the variable-nutation method [20]. All of the SPGR scans were coregistered prior to T1 map computation to compensate for slight movement of the animal during infusion. Concentration maps were then computed from each pair of scans as described in [18]. Briefly, the equation $1 / \mathrm{T} 1=1 / \mathrm{T} 1_{0}+\mathrm{R}_{1} \cdot \mathrm{C}$, is used, where $T 1_{0}$ is the preinfusion $T 1, R_{1}$ is the gadoteridol T1 relaxivity, and $\mathrm{C}$ is the concentration. Gadoteridol relaxivity was calibrated by imaging vials of known concentration, and was estimated to be $3.7 \mathrm{mmol} / \mathrm{l} / \mathrm{s}$. The minimum concentration that could be reliably estimated by this method was $0.05 \mathrm{mmol} / \mathrm{l}$. The total amount of gadoteridol tracer in a region (in nanomoles) is computed from the concentration maps by summing over the measured concentration at each voxel within the region (in nanomoles/microliter) and multiplying by the volume represented by each voxel (in microliters).

Segmentation of the Putamen. In each subject, the putamen was delineated by hand from a high-resolution T1W scan $(0.27 \times$ $0.27 \times 0.4 \mathrm{~mm}$ voxel resolution) guided by a rhesus MRI brain atlas [21]. Each voxel in the scan was classified as either 'in' or 'out' of the putamen, resulting in a $3 \mathrm{D}$ binary volume identifying the putamen. The putamen segmentation was used to classify each voxel in the concentration maps, and thus to obtain estimates of the total amount of gadolinium inside and outside of the putamen at each measurement (i.e. at 9-min time intervals).

MRI Angiography Processing. MRI angiography was acquired with and without contrast, allowing digital subtraction in order to enhance the signal of the vasculature. The vessels of the NHP putamen are small relative to the imaging resolution. Their identification is further complicated by spatial variations in signal intensity across the images mainly due to RF inhomogeneity of the surface coil. We therefore computed the ratio of the contrast and noncontrast images (rather than the difference), obtaining nor- malized vascular imagery. The data were windowed to the range $1.15-1.3$, corresponding to $15-30 \%$ signal enhancement in the contrast images. Where classification of vessels was required, a threshold of 1.19 was used to classify vessels in the NHP putamen.

Loss Quantification. Based on the putamen segmentation, infusion concentration outside the structure was considered infusate loss and was reported as loss fraction, which is the ratio of the amount classified as loss to the total amount.

Backflow Distance. Infusate following the catheter shaft was considered backflow and it was measured from the tip of the catheter to the most proximal point of enhancement along the shaft. Backflow was visible in the T1W MRI usually within a few minutes after the start of the infusion. As the infusion continued, the backflow region became obscured by the growing infusion cloud. Thus, the backflow distance was measured in the first available T1W acquisition after the start of infusion.

Catheter Depth Measurements. The catheter depth was defined to be the length of catheter lying within the putamen, and it was measured as the distance along the catheter from the tip to the border of the putamen.

\section{Results}

In all cases, the ventral postcommissural putamen target was reached, as defined in the presurgical planning [19]. Four typical pathways for infusate loss were identified and measured: overflow, perivascular flow, backflow, and catheter tract leakage.

\section{Overflow}

Evaluation of T1 MRIs in the coronal, axial, and sagittal planes revealed that early in the infusion, distribution of infusate generally consisted of a symmetric portion, in which the measureable pattern extended a constant distance from the catheter tip, and sometimes had asymmetric portions that partially followed the catheter shaft or an artery previously identified in the baseline angiography. As the infusion continued and passed the 30- $\mu \mathrm{l}$ volume, the pattern of distribution in all 22 infusions went beyond the putaminal borders. The putamen did not appear to offer any particular barrier to this path of loss. However, the onset of leakage past the putamen boundaries did not stop further spread within the putamen; the amount in the putamen continued to increase throughout the infusion.

Over the 22 infusions, we found that all infusions began to show some measurable amount of loss by the time $30 \mu \mathrm{l}$ were infused. Measured loss for each infusion is given in table 1 . Nine of the 22 infusions had a loss of $14 \%$ or less at $30 \mu \mathrm{l}$ of infusion. This limit is not surprising, owing to the narrow width of the NHP putamen. All catheter placements were at most $2.5 \mathrm{~mm}$ from the near- 

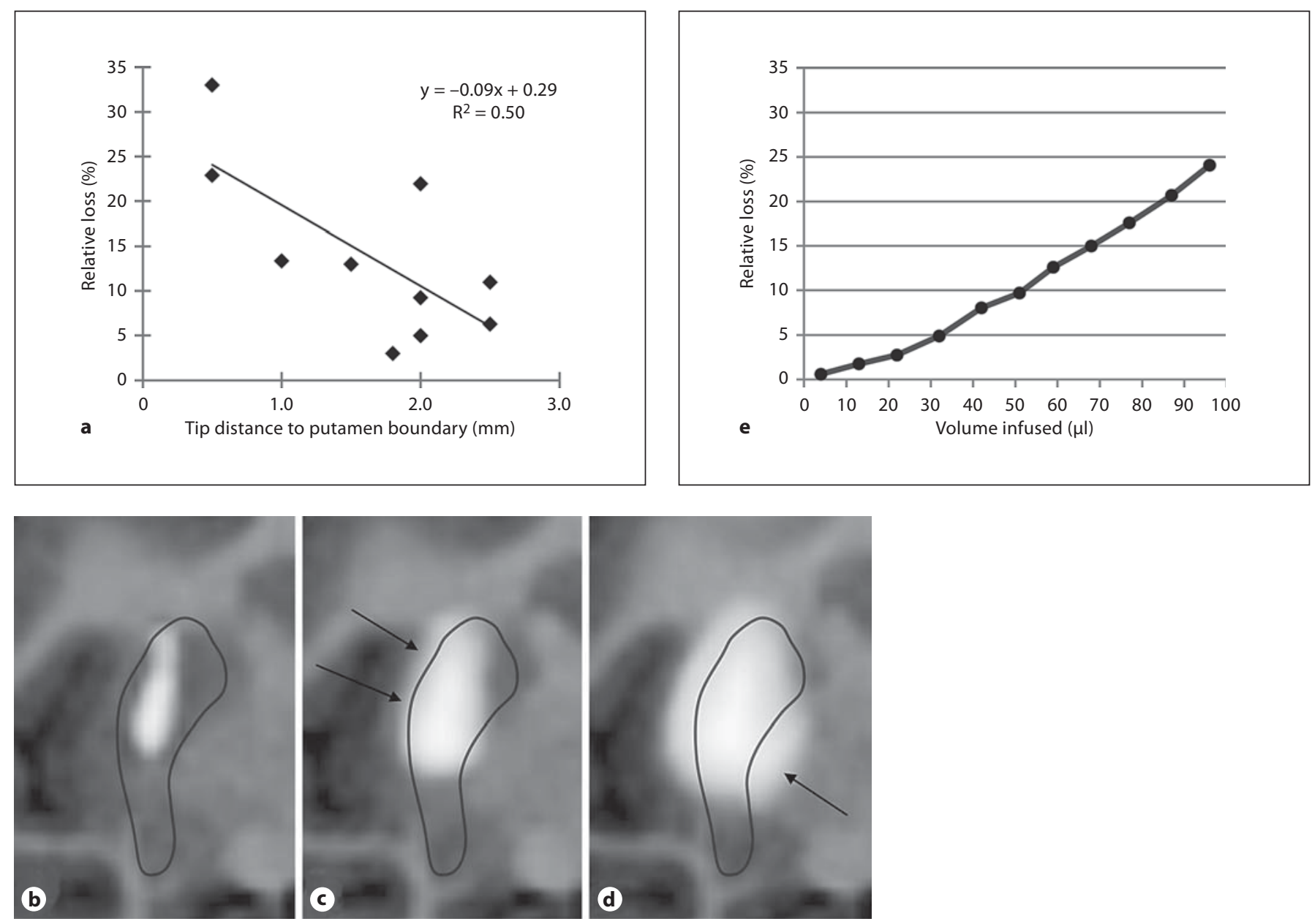

Fig. 1. Illustration of overflow loss. a Correlation between the distance of the catheter tip to the nearest putamen boundary and the fraction of measured gadolinium outside the putamen after $30 \mu \mathrm{l}$ of infusion for 10 infusions dominated by overflow. b-d Quantitative T1 maps (negated) for a specific example (Cy0298-left) centered at the catheter tip during the infusion of $100 \mu \mathrm{l}$ (infusion rate: $1 \mu \mathrm{l} / \mathrm{min}$ ) show infusate overflow out of the putamen over time. b Six millimeters of backflow contained within the putamen

was detected a few minutes after the start of the infusion. c At 32 min, infusate begins to move past the medial edge of the putamen. d At the end of the 100-min infusion, the tracer begins to spread into the external capsule on the lateral side of the putamen (arrows). e Plots of the computed amount of tracer outside the putamen divided by the total measured amount at approximately 10 min intervals (Cy0298).

est putamen boundary (average $1.6 \pm 0.7 \mathrm{~mm}$ ). In most cases, the volume of tissue containing detectable amounts of tracer was at least $150 \mu \mathrm{l}$ by this time $\left(\mathrm{V}_{\mathrm{d}} / \mathrm{V}_{\mathrm{i}}>5\right)$. The radius of a $150-\mu \mathrm{l}$ ball is approximately $3.3 \mathrm{~mm}$, and thus any roughly spherical distribution would start to overflow the putamen by the time $30 \mu \mathrm{l}$ is infused. After excluding 4 infusions that had backflow loss and 8 that had significant perivascular loss (>10\%) at $30 \mu \mathrm{l}, 10$ remaining infusions had dominant overflow losses (R95106right, R03044-both, R03064-both, Cy0288-right, Cy0298-both, Cy0299-left, Cy0279-left). In these 10 infu- sions, overflow loss was inversely correlated with catheter tip distance from the nearest putamen boundary at both 30 and $100 \mu \mathrm{l}$ of infusion (fig. $1 \mathrm{a} ; \mathrm{R}^{2}=0.50, \mathrm{p}=0.02$ ).

Cy0298-left (fig. 1b-e) is a typical case in which the catheter was placed in its left ventral postcommissural putamen target, $7 \mathrm{~mm}$ deep into the structure (from the tip of the catheter to its point of entry into the putamen). The tip was approximately $1.6 \mathrm{~mm}$ from the nearest putamen boundary. At $4 \mathrm{~min}$, or $4 \mu \mathrm{l}$ of infusion, some infusate was observed following the catheter shaft (backflow distance: $6 \mathrm{~mm}$; fig. $1 \mathrm{~b}$ ) yet it remained inside the 


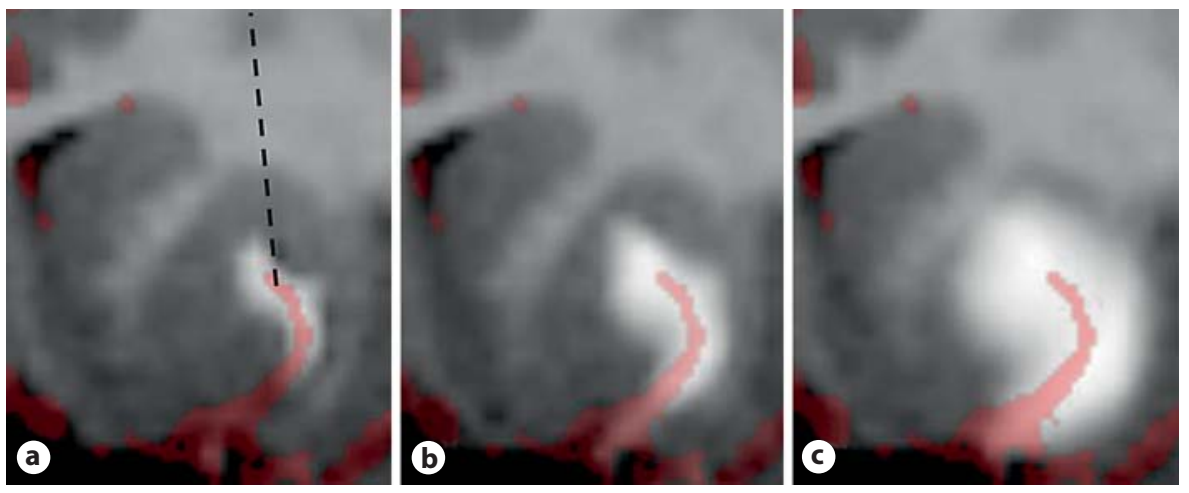

Fig. 2. Example of perivascular loss (Cy0287-right). T1 maps (negated) were resliced obliquely at approximately $45^{\circ}$ between the coronal and axial planes, so that an artery located near the catheter tip is visible. MR angiography is coregistered and overlaid, illustrating the location of the nearby artery and the correlation of the asymmetric flow to the path of the artery. a Ten minutes after the start of infusion, the highly asymmetric flow is visible. The projection of the catheter into this oblique plane is shown (dashed line). The catheter itself lies in the coronal plane. The infusion continues to expand laterally as the infusion proceeds, as shown in b, 27 min after the start of infusion, and c, 95 min after the start of infusion. d Plots of the computed amount of tracer outside the putamen along a blood vessel divided by the total measured amount at approximately 10-min intervals (Cy0287).

structure, following a symmetrical elongated shape. At 32 min, it reached both the lateral and medial putamen edges, and began to escape at the medial edge into the globus pallidus (arrows, fig. 1c). Near the end of the infusion at $96 \mathrm{~min}$ (96 $\mu$ l infused) infusate crossed the lateral boundary into the external capsule (arrow, fig. 1d). At $32 \mathrm{~min}$, about $5 \%$ of the measured gadoteridol was lost outside the putamen (fig. 1e). After this time, the rate of loss increased as the infusion reached more of the putamen boundary and entered the adjacent structures, including the globus pallidus and the external capsule. At $96 \mathrm{~min}$, the fraction of measured tracer within the putamen fell to $76 \%$. Of the $24 \%$ of infusate outside the putamen, approximately $8 \%$ was lost into the globus pallidus, and another $8 \%$ along the external capsule.

\section{Perivascular Loss}

During infusion, patterns of asymmetric flow that resembled blood vessel branching were frequently observed. When the imaging of the infusate pattern was matched to baseline angiography, it confirmed that these asymmetric infusate distributions corresponded to the

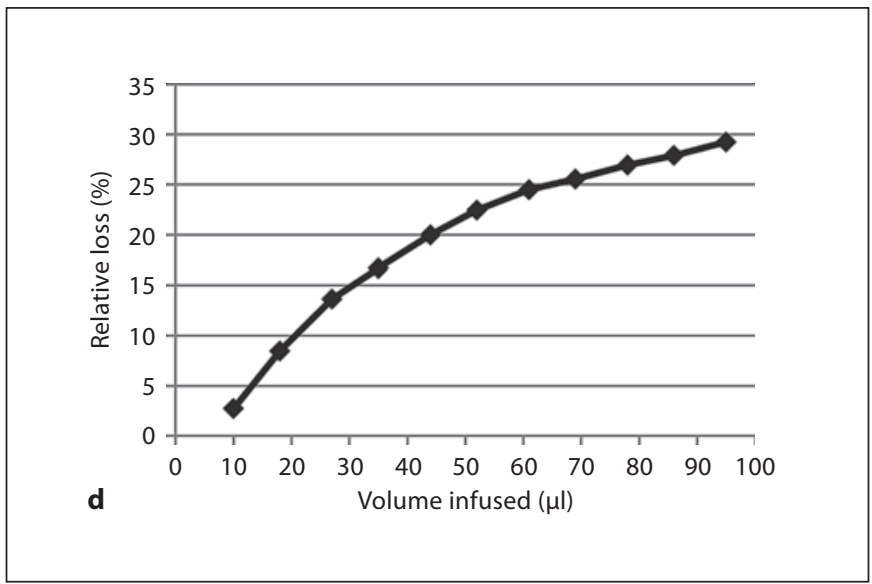

path of a blood vessel. The putamen nucleus is highly irrigated by branches of the lenticulostriate arteries (mostly rostral and medial putamen) and the anterior choroidal arteries (caudal sections) [22]. In 15 out of 22 infusions, during the first $30 \mu \mathrm{l}$ of infusion, we observed lenticulostriate loss shunting fluid away from the putamen. At this time point, the loss fraction among these 15 cases varied greatly, from 1 to $35 \%$, with 5 infusions having a perivascular loss of over $20 \%$. The average loss over all 22 infusions was $9.4 \pm 10.9 \%$. Table 1 gives the estimated perivascular loss along a lenticulostriate artery after $30 \mu \mathrm{l}$ of infusion. The perivascular loss measurements were performed at this early time point because once past $30 \mu \mathrm{l}$, overflow in the same region in some of the infusions makes it difficult to ascribe a given amount to being along the blood vessel. Infusions performed near the anterior choroid arteries toward the most posterior putamen section also resulted in a similar asymmetric pattern of infusate loss, but these were less common in our catheter trajectories.

Cy0287-right (fig. 2) is an example of flow along a lenticulostriate branch. These vessels typically do not lie 

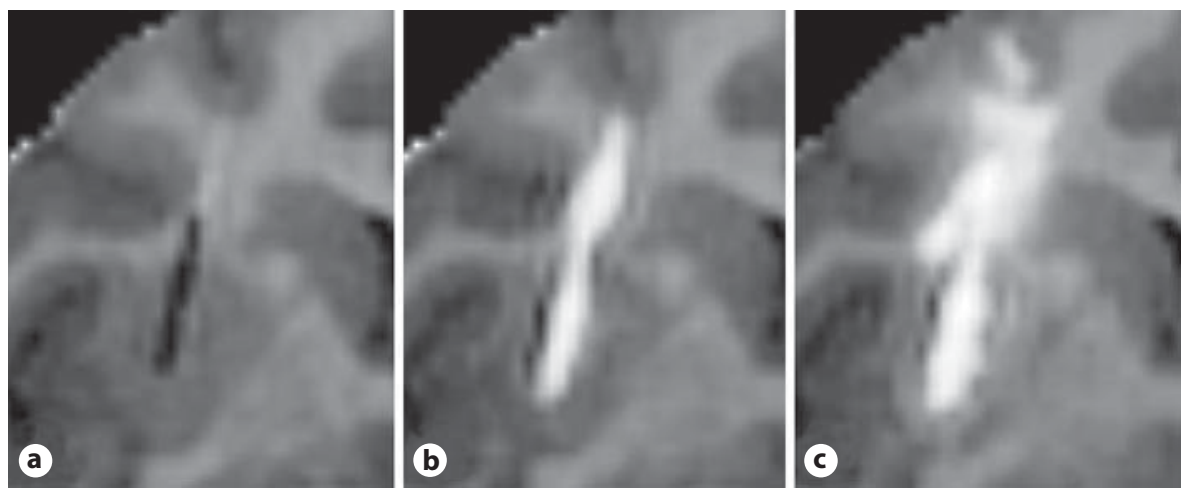

Fig. 3. Extreme example of backflow loss (Cy0140-left). Coronal T1 maps (negated) centered at the catheter position illustrate that backflow along the catheter shaft can be a major cause of infusate loss out of the putamen. In this extreme example, about $70 \%$ of the infusate flows outside of the NHP putamen. a Shows the preinfusion catheter position. b Backflow is clearly developed outside the putamen, $13 \mathrm{~mm}$ from the catheter tip, at $18 \mathrm{~min}$. c Most of the infusate flows out the top of the putamen and spreads through the frontal white matter tracts above the putamen as the infusion continues. $\mathbf{d}$ Plots of the computed amount of tracer outside the putamen divided by the total measured amount at approximately 10-min intervals (Cy0140).

within the imaging plane, thus 3D imaging data were resliced obliquely at an orientation between the axial and coronal planes in order to observe a portion of the artery near the catheter in a single image. In figure $2 a$, such an oblique slice of the brain is shown, 10 min after the start of the infusion. The projection of the line of the catheter onto this plane is shown, but the shaft is in fact out of the plane of the image, making approximately a 45 -degree angle with the plane shown. The tip of the catheter was centered within the main ball of the infusion. A highly asymmetric flow was observed from the start of the infusion. In figure $2 b$, the coregistered angiography image is overlaid, showing that the asymmetry correlates with the path of a lenticulostriate artery. As the infusion continued, there was expansion about the main infusion ball around the catheter, and about the asymmetric projection along the lenticulostriate path (fig. 2c). The flow followed the perivascular space for a limited distance, and then spread out 'cylindrically' from an annular source of fluid surrounding the vessel. In this case, the fraction of loss out of the putamen continued to increase (fig. 2d) when the boundary of the putamen was reached.

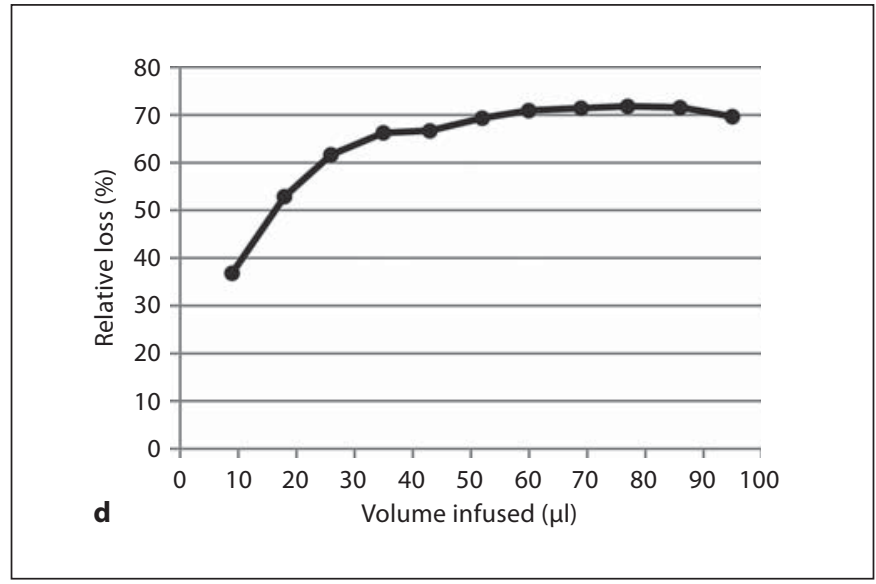

Backflow

Asymmetric infusate distribution following the catheter shaft was observed during all infusions. Yet, there were only 4 cases (Cy0140-left, Cy0295-right, R5008right, Cy0288-left) out of the 22 infusions observed in which the backflow reached or extended beyond the top boundary of the putamen. In these 4 cases, the fraction of total dose lost along the backflow pathway increased over the first 30-60 min to a peak value and remained relatively stable after $60 \mathrm{~min}$ (table 1). In 3 out of the 4 cases (Cy0295-right, R5008-right, Cy0288-left), the fractional loss was clustered close to $35 \%$ on the average, ranging from 30 to $40 \%$. In the 4 th case (Cy0140-left), high backflow loss was $70 \%$, which was atypical for the device and low flow rate protocol used (fig. 3). The catheter was placed $6 \mathrm{~mm}$ deep in the putamen, with the tip $2 \mathrm{~mm}$ from the nearest putamen boundary (fig. 3a). The backflow was visible in MRI within 9 min from the start of the infusion (fig. 3b). The backflow distance along the catheter shaft was $16 \mathrm{~mm}$, far beyond the top boundary of the putamen. About $70 \%$ of the measured gadoteridol was lost into the white matter surrounding the catheter, 


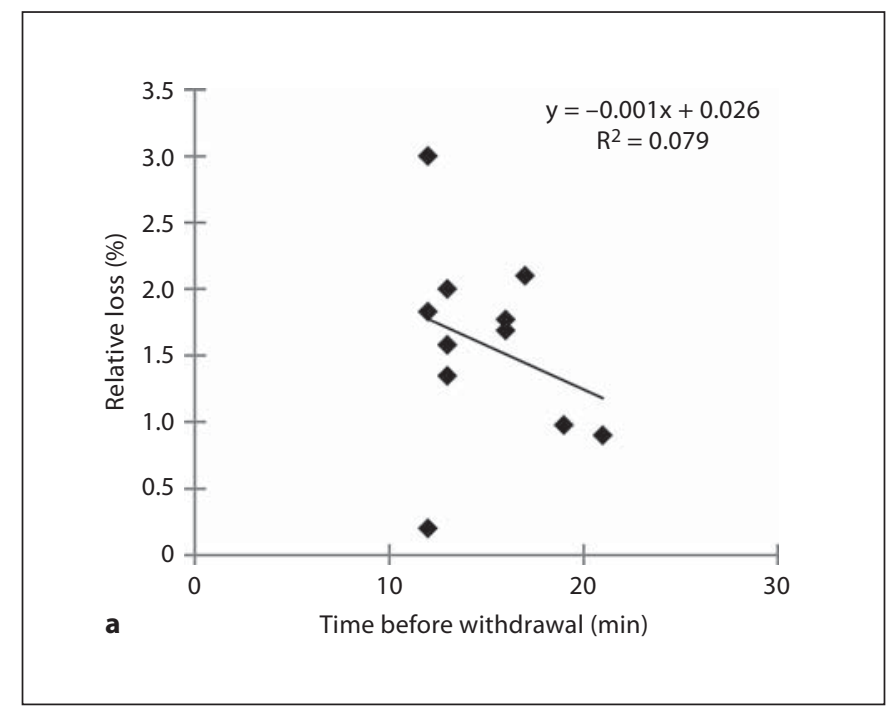

Fig. 4. Illustration of leakage into the catheter tract. a Correlation between time before catheter withdrawal and fraction of infusate found to leak into the catheter track shows little correspondence.

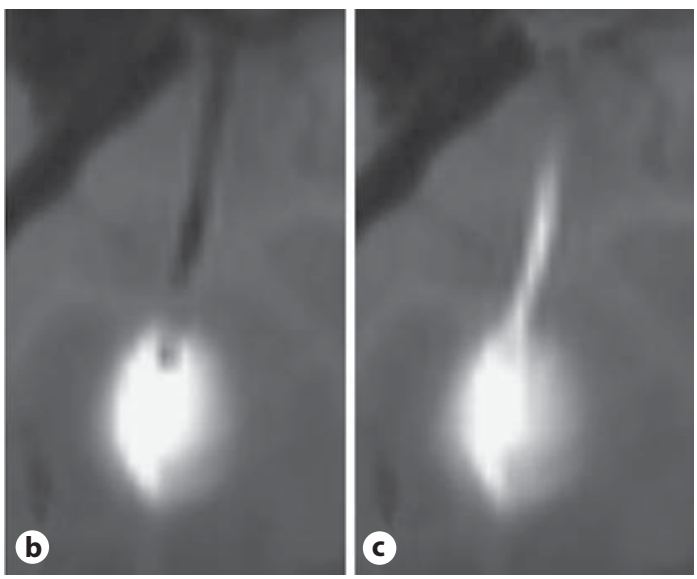

b, c Coronal T1W MRI images of one example (Cy0286-left) at the end of infusion before withdrawing the catheter (b) and $30 \mathrm{~min}$ after withdrawal of the catheter (c). superior to the putamen (fig. 3c, d). The fractional loss stabilized at this rate after about $30 \mathrm{~min}$ of infusion. While the loss was considerable, most of the remaining $30 \%$ of the infusate concentration remained within the putamen, and the total dose in the putamen increased throughout the infusion (albeit at a reduced rate). Thus, continued infusion also continues to fill the putamen at this fraction while losses from other causes are not present.

A certain amount of variability in backflow distance arises from variation in biological properties. The average backflow distance ( \pm standard deviation) over all 22 infusions was $5.0 \pm 3.4 \mathrm{~mm}$, ranging from 2 to $16 \mathrm{~mm}$. However, backflow that exits the putamen is affected by the tissue properties of the white matter outside the putamen. For the 18 infusions in which the backflow remained within the putamen, the average backflow distance was $3.8 \pm 1.0 \mathrm{~mm}$. On average, the depth of catheter placement within the putamen was $6.2 \pm 1.1 \mathrm{~mm}$, which was usually sufficient to avoid backflow out of the putamen at the low flow rate $(1 \mu \mathrm{l} / \mathrm{min})$ employed.

\section{Leakage into the Catheter Tract}

Ten to $30 \mathrm{~min}$ after the infusions were completed, the catheters were extracted (table 1). Subsequent imaging revealed leakage of tracer along the full length of the catheter tract in all cases (table 1). In 1 case (Cy0279-left), the stylet was replaced just before catheter withdrawal, and yet infusate was still observed in the catheter tract. Eleven of the infusions had imaging that allowed quantitative measurement of the amount in the catheter track (R03044right, R03064-right, Cy0286-left, Cy0287-right, Cy0298left, Cy0299-left, Cy0279-left, Cy0288-left, Cy0295-left, Cy0299-right, and Cy0279-right). The mean measured amount in the catheter track was $1.6 \pm 0.7 \%$ of the total infused amount. The loss did not vary significantly with the waiting time before withdrawal in the 10 - to $30-\mathrm{min}$ range (fig. 4a; $\mathrm{R}^{2}=0.08, \mathrm{p}=0.40$ ).

Cy0286-left (fig. 4b, c) is an example of leakage into the catheter tract after waiting 16 min before retracting the catheter. Tracer appeared to be drawn up the tract by the catheter during its withdrawal. MRI measurement of the gadolinium deposited in the track in this example yielded an estimate of $3.6 \mathrm{nmol}$, which is the amount of gadolinium contained in $1.8 \mu \mathrm{l}$ of infusate, $1.8 \%$ of the infused amount.

\section{Conclusions and Discussion}

This study demonstrates, during CED into ventral postcommissural putamen nucleus of macaque monkeys, four main paths for infusate loss outside of the target area: overflow, perivascular flow, backflow and catheter tract leakage. It also demonstrates the value of IMRI for replicable intracerebral targeting; 22 of 22 cases had cath- 
eter placements in the planned region of interest. Quantification of the magnitude of the loss by IMRI monitoring suggests that infusate volume and regional vasculature are the main factors for infusate loss in the NHP brain and provide insight of possible issues that can affect the success of human studies.

It could be argued that the data obtained in monkeys has limited application to the larger human brain. While it is true that the human putamen is approximately six times larger in volume than our average monkey, it has a more elongated shape, further complicating a strategy of coverage via a single spherical infusion. The rhesus putamen is not much narrower in the postcommissural region than that of the human [23]. This implies that for clinical trials, similar to our study, it will be difficult to place a catheter more than a few millimeters from the nearest lateral boundary and thus overflow loss from the human putamen will occur before high coverage of the nucleus is reached. Considering these limitations, it seems that multiple inoculations sites are needed to reach therapeutic coverage of the putamen.

Some investigators have proposed that perivascular flow is a major mechanism responsible for intracerebral distribution of infusates [24]. In our study, blood vessels were associated with asymmetric infusate distributions that were an apparent pathway of loss. Blood vessel distribution limits the selection of sites for optimal catheter position, as they should be avoided in order to limit perivascular leakage. In NHPs, the largest vessels were usually found in the anterior half of the putamen, whereas in humans, the large vessels are more widely distributed [22], which may make them more difficult to avoid.

Previous studies have identified backflow as having a potentially important role in loss and misdistribution of infusate. Although we observed some amount of backflow in all of the cases, the loss along this path was only significant in 4 cases in which the backflow extended past the putamen boundary into the adjacent corona radiata. The intraputaminal depth of the catheter was a variable that for our study had to be adjusted by subject and seemed to affect the capacity to contain the backflow inside the structure. The greater height of the human putamen along the usual superior/inferior catheter trajectory should allow for deeper catheter placements, and thus lowered risk of backflow loss. We deliberately selected a low flow rate $(1 \mu \mathrm{l} / \mathrm{min})$ that limited the chance of backflow out of the putamen in our study. However, some prior and proposed human trials have used significantly larger flow rates and catheter diameters than used in our animal study. Both factors tend to increase the backflow distance and with it the risk of backflow loss into the white matter. An axial catheter trajectory passing through the frontal sinuses was previously used in a Parkinson's disease clinical trial using fetal tissue for cell replacement [25]. This approach is not commonly used due to its risk of damage to the frontal lobe, but it might have a geometric advantage, in that a catheter could be inserted along the long axis of the putamen and take advantage of the elongation of the distribution due to backflow. It should be noted that it is not feasible to test the frontal insertion angle in macaques due to their extensive skull bone mass at the required entry point.

Catheter tract leakage of infusate was observed along the path of the withdrawn catheter in all cases. This pattern was found even after waiting up to $30 \mathrm{~min}$ after infusion before retracting the catheter. This loss is likely to occur during human infusions, especially if the catheter is removed shortly after infusion. While the infusate loss in monkeys was limited to a few microliters, it should be taken into consideration in the case of delivering gene therapy, as the presence of viral vectors may induce undesired accumulation of proteins in nontarget areas over time. We have observed that if the stylet is replaced after infusion in order to seal the catheter from leakage during withdrawal, the loss into the track is not reduced. Thus, the source of the infusate must be from the infusate already in the tissue. The rapid appearance of this leakage indicates that it is pressure driven, rather than diffusing. This could be due to a vacuum created from catheter withdrawal. Alternately, the pressure of convection tends to expand the tissue during infusion, and the tissue relaxing back to its original shape may provide some of the convective pressure. Further delayed catheter removal in acute infusion systems may mitigate this loss and add safety to the infusion protocol. However, in our studies, a delay of up to $30 \mathrm{~min}$ was insufficient to mitigate the effect.

The characteristics of the infusate should be considered when analyzing distribution patterns. To facilitate our analysis, we utilized in all our infusions the same gadoteridol infusate solution. Gadoteridol has a molecular weight of 558.7 Da. The use of proteins or viral vectors of greater molecular size, electric charge, as well as concentration/vector titer and different biological properties (such as receptor affinity) will have to be considered when planning intraputaminal deliveries.

To conclude, our analyses demonstrate that after controlling for targeting, catheter type, infusion rate and infusate characteristics, the main issues during surgical planning are the identification of appropriate infusate 
volume that matches the target area, as well as mapping the regional vasculature as it may become a pathway for infusate loss. Most importantly, these results underscore the significance of presurgical planning for catheter placement and infusion methods as well as the value of imaging guidance to ensure targeting accuracy.

\section{Acknowledgements}

This research was supported by the Kinetics Foundation and NIH-NCRR grant P51 RR000167 (Wisconsin National Primate Research Center, University of Wisconsin-Madison) and was conducted at a facility constructed with support from Research Facilities Improvement Program grants RR15459-01 and RR020141-01.

\section{References}

$>1$ Lang AE, Gill S, Patel NK, Lozano A, Nutt JG, Penn R, Brooks DJ, Hotton G, Moro E, Heywood P, Brodsky MA, Burchiel MA, Dalvi KP, Scott B, Stacy M, Turner D, Wooten VG, Elias WJ, Laws ER, Dhawan V, Stoessl AJ, Matcham J, Coffey RJ, Traub M: Randomized controlled trial of intraputaminal glial cell line-derived neurotrophic factor infusion in Parkinson disease. Ann Neurol 2006;59:459-466.

-2 Marks WJ, Bartus RT, Siffert J, Davis CS, Lozano A, Boulis N, Vitek J, Stacy M, Turner D, Verhagen L, Bakay R, Watts R, Guthrie B, Jankovic J, Simpson R, Tagliati M, Alterman R, Stern M, Baltuch G, Starr PA, Larson PS, Ostrem JL, Nutt J, Kieburtz K, Kordower JH, Olanow CW: Gene delivery of AAV2-neurturin for Parkinson's disease: a double-blind, randomized, controlled trial. Lancet Neurol 2010;9:1164-1172.

-3 Nutt JG, Burchiel KJ, Comella CL, Jankovic J, Lang AE, Laws JE, Lozano AM, Penn RD, Simson JR, Stacy M, Wooten GF: Randomized, double-blind trial of glial cell line-derived neurotrophic factor (GDNF) in PD. Neurology 2003;60:69-73.

-4 Patel NK, Bunnage M, Plaha P, Svendsen CN, Heywood P, Gill SS: Intraputamenal infusion of glial cell line-derived neurotrophic factor in PD: a two-year outcome study. Ann Neurol 2005;57:298-302.

$\checkmark 5$ Richardson RM, Kells AP, Rosenbluth KH, Salegio EA, Fiandaca MS, Larson PS, Starr PA, Martin AJ, Lonser RR, Federoff HJ, Forsayeth JR, Bankiewicz KS: Interventional MRI-guided putaminal delivery of AAV2GDNF for a planned clinical trial in Parkinson's disease. Mol Ther 2011;19:1048-1057.

6 Slevin JT, Gerhardt GA, Smith CD, Gash DM, Kryscio R, Young B: Unilateral intraputamenal GDNF improves bilateral motor functions in patients with Parkinson's disease. J Neurosurg 2005;102:216-222.

7 Marks WJ, Ostrem JL, Verhagen L, Starr PA, Larson PS, Bakay RAE, Taylor R, CahnWeiner DA, Stoessl AJ, Olanow CW, Bartus RT: Safety and tolerability of intraputaminal delivery of CERE-120 (adeno-associated virus serotype 2-neurturin) to patients with idiopathic Parkinson's disease: an open-label, phase I trial. Lancet Neurol 2008;7:400408.
>8 Morrison PF, Lonser RR, Oldfield EH: Convective delivery of glial cell line-derived neurotrophic factor in the human putamen. J Neurosurg 2007;107:74-83.

$\checkmark 9$ Bartus RT, Herzog CD, Chu Y, Wilson A, Brown L, Siffert J, Johnson JEM, Olanow CW, Mufson EJ, Kordower JH: Bioactivity of AAV2-neurturin gene therapy (CERE-120): differences between Parkinson's disease and nonhuman primate brains. Mov Disord 2011;26:27-36.

10 Emborg ME, Moirano J, Raschke J, Bondarenko V, Zufferey R, Peng S, Ebert AD, Joers V, Roitberg B, Holden JE, Koprich J, Lipton J, Kordower JH, Aebischer P: Response of aged parkinsonian monkeys to in vivo gene transfer of GDNF. Neurobiol Dis 2009;36:303311.

11 Kirik D, Georgievska B, Björklund A: Localized striatal delivery of GDNF as a treatment for Parkinson disease. Nat Neurosci 2004;7: 105-110.

12 Bobo RH, Laske DW, Akbasak A, Morrison PF, Dedrick RL, Oldfield EH: Convectionenhanced delivery of macromolecules in the brain. Proc Natl Acad Sci USA 1994;91:20762080.

13 Kimmelman J, Duckworth K, Ramsay T, Voss T, Ravina B, Emborg M: Risk of surgical delivery to deep nuclei: a meta-analysis. Mov Disord 2011;26:1415-1421.

14 Sampson JH, Archer G, Pedain C, Wembacher-Schroder E, Westphal M, Kunwar S, Vogelbaum MA, Coan A, Herndon II JE, Raghavan R, Brady ML, Reardon DA, Friedman AH, Friedman HS, Rodriguez-Ponce MI, Chang SM, Mittermeyer S, Croteau D, Puri RK: Poor drug distribution as a possible explanation for the results of the PRECISE trial. J Neurosurg 2010;113:301-309.

15 Morrison PF, Laske DW, Bobo H, Oldfield EH, Dedrick RL: High-flow microinfusion: tissue penetration and pharmacodynamics. Am J Physiol 1994;266:R292-R305.
16 Morrison PF, Chen MY, Chadwick RS, Lonser RR, Oldfield EH: Focal delivery during direct infusion to brain: role of flow rate, catheter diameter, and tissue mechanics. Am J Physiol 1999;277:R1218-R1229.

17 Krauze MT, Saito R, Noble C, Bringas J, Forsayeth J, McKnight TR, Park J, Bankiewicz KS: Effects of the perivascular space on convection-enhanced delivery of liposomes in primate putamen. Exp Neurol 2005;196: 104-111.

18 Brady ML, Raghavan R, Chen Z, Broaddus W: Quantifying Fluid Infusions and Tissue Expansion in Brain. IEEE Trans Biomed Eng 2011;58:2228-2237.

19 Emborg ME, Joers V, Fisher R, Brunner K, Carter V, Ross C, Raghavan R, Brady M, Raschke J, Kubota K, Alexander A: Intraoperative intracerebral MRI-guided navigation for accurate targeting in nonhuman primates. Cell Transplant 2010;19:1587-1597.

20 Deoni S, Peters T, Rutt B: Determination of optimal angles for variable nutation spin-lattice, T1, and spin-spin, T2, relaxation times measurement. Mag Reson Med 2004;51: 428-433.

21 Saleem KS, Logothetis NK: A Combined MRI and Histology Atlas of the Rhesus Monkey Brain in Stereotaxic Coordinates. London, Academic Press, 2006.

22 Donzelli R, Marinkovic S, Brigante L, de Divitiis $\mathrm{O}$, Nikodijevic I, Schonauer C, Maiuri F: Territories of the perforating (lenticulostriate) branches of the middle cerebral artery. Surg Radiol Anat 1998;20:393-398.

23 Yin D, Valles F, Fiandaca M, Forsayeth J, Larson P, Starr P, Bankiewicz K: Striatal volume differences between non-human and human primates. J Neurosci Methods 2009;176: 200-205.

24 Hadaczek P, Yamashita Y, Mirek H, Tamas L, Bohn MC, Noble C, Park JW, Bankiewicz K: The 'perivascular pump' driven by arterial pulsation is a powerful mechanism for the distribution of therapeutic molecules within the brain. Mol Ther 2006;14:69-78.

-25 Freed C, Greene P, Breeze R, Tsai WY, DuMouchel W, Kao R, Dillon S, Winfield H, Culver S, Trojanowski J, Eidelberg D, Fahn S: Transplantation of embryonic dopamine neurons for severe Parkinson's disease. N Engl J Med 2001;344:710-719. 